\title{
Comparisons of Limb Structural Properties in Free-Ranging Chimpanzees From Kibale, Gombe, Mahale and Taï Communities
}

\section{Citation}

Carlson, K. J., Richard W. Wrangham, M. N. Muller, D. R. Sumner, M. E. Morbeck, T. Nishida, A. Yamanaka, and C. Boesch. 2010. Comparisons of limb structural properties in free-ranging chimpanzees from Kibale, Gombe, Mahale and Taï communities. In Primate Locomotion: Linking Field and Laboratory Research. Developments in Primatology: Progress and Prospects, ed. K. D'Août and E. E. Vereecke, 155-182. New York: Springer.

\section{Published Version}

doi:10.1007/978-1-4419-1420-0

\section{Permanent link}

http://nrs.harvard.edu/urn-3:HUL.InstRepos:5347701

\section{Terms of Use}

This article was downloaded from Harvard University's DASH repository, and is made available under the terms and conditions applicable to Other Posted Material, as set forth at http:// nrs.harvard.edu/urn-3:HUL.InstRepos:dash.current.terms-of-use\#LAA

\section{Share Your Story}

The Harvard community has made this article openly available.

Please share how this access benefits you. Submit a story.

Accessibility 
Comparisons of limb structural properties in free-ranging chimpanzees from Kibale, Gombe, Mahale, and Taï communities

KJ Carlson ${ }^{1}$, RW Wrangham ${ }^{2}$, MN Muller ${ }^{3}$, DR Sumner ${ }^{4}$, ME Morbeck ${ }^{5}$, T Nishida ${ }^{6}$, A Yamanaka $^{7}, \mathrm{C}$ Boesch $^{8}$

${ }^{1}$ Department of Anatomy, New York College of Osteopathic Medicine, USA. ${ }^{2}$ Department of Anthropology, Harvard University, USA. ${ }^{3}$ Department of Anthropology, University of New Mexico, USA. ${ }^{4}$ Department of Anatomy and Cell Biology, Rush Medical College, USA.

${ }^{5}$ Department of Anthropology, University of Arizona, USA. ${ }^{6}$ Mahale Mountains Chimpanzee

Research Project, Kyoto University, Graduate School of Science. ${ }^{7}$ Department of Oral Anatomy, Kagoshima University Dental School, Japan. ${ }^{8}$ Max-Planck Institute for Evolutionary Anthropology, Leipzig, Germany.

Corresponding author: KJ Carlson, Department of Anatomy, New York College of Osteopathic Medicine, Northern Boulevard, Old Westbury, NY 11568-8000, USA. Telephone: (516) 6863771. E-mail: kcarlson@nyit.edu

Text: 19 pages, plus references ( 9 pages)

Figure: 1, plus figure captions (1 page)

Tables: 10 (14 pages)

Granting agencies: L.S.B. Leakey Foundation. 


\begin{abstract}
Structural characteristics of limbs bones provide insight into how an animal dynamically loads its limbs during life. Cause-and-effect relationships between loading and the osteogenic response it elicits are complex. In spite of such complexities, cross-sectional geometric properties can be useful indicators of locomotor repertoires. Typical comparisons use primates that are distinguished by broad habitual locomotor differences, usually with samples garnered from several museum collections. Intraspecific variability is difficult to investigate in such samples because behavior or life histories, which are tools for interpreting intraspecific variability, are limited. Clearly intraspecific variation both in morphology and behavior/life history exists. Here we expand an ongoing effort towards understanding intraspecific variation in limb structural properties by comparing free-ranging chimpanzees that have associated behavioral and life history data. Humeral and femoral data from eleven adult chimpanzees (Pan troglodytes) of Kibale National Park (Uganda) are compared to 29 adult habituated chimpanzees from Gombe (Tanzania), Mahale Mountains (Tanzania), and Taï Forest (Côte d'Ivoire) National Park communities. Overall, limb structural morphology of Kibale chimpanzees most resembles limb structural morphology of Mahale chimpanzees. Shape ratios and percentage cortical areas of Kibale chimpanzees are most similar to non-Gombe chimpanzees, while Kibale structural properties (e.g., maximum rigidity) are most similar to non-Taï structural properties. Even after adding Kibale females, Taï females continue to stand out from females in other communities. This research was supported in part by the L.S.B. Leakey Foundation and the National Science Foundation (DDIG, BCS-0002686).
\end{abstract}

Keywords: cross-sectional geometry, functional morphology, Pan troglodytes, locomotor behavior 
Functional morphologists rely on comparative approaches as well as experimental techniques in the laboratory (i.e., kinetics, kinematics, electromyography, strain analysis) in order to understand form-function relationships in the postcranium of animals. Shared or unique components of activity patterns provide a framework against which morphological commonalities or differences are evaluated. Often times, comparative studies construct samples from specimens of museum collections (Green et al., 2007; Haeusler and McHenry, 2007; Marchi, 2007; Ruff, 2002, 2008). While museum specimens may be numerous and accessible two criteria necessary for amassing large samples that rigorous statistical analyses favor - they also necessitate a seldom-appreciated tradeoff, namely, that while behavior and life history may vary among group individuals, this variation must be ignored in order to compare groups. Clearly, however, individuals within populations can vary substantially in behavioral or life history variables (Goodall, 1986; Hunt, 1992), which may in turn contribute to intragroup variability in morphological characteristics and reproductive fitness.

Chimpanzees (Pan troglodytes) offer a unique opportunity among animals to address functional morphology questions. Observational studies of free-ranging chimpanzee communities provide a detailed portrait of individual life histories (Boesch and BoeschAchermann, 2000; Goodall, 1986; Morbeck, 1999; Nishida, 1990; Morbeck et al., 2002). Studies encompassing the last 45 years at several locations [i.e., Gombe Stream National Reserve (Tanzania), Kibale National Park (Uganda), Mahale Mountains National Park (Tanzania), and Taï Forest National Park (Côte d'Ivoire)] document activity profiles of female and male chimpanzees of all ages in all sorts of situations or settings. Skeletal collections have slowly accumulated in the same communities, and thus frequently, individual specimens can be associated with contextual information, e.g., life history, activity, and habitat data. Such a 
sample is ideal for investigating form-function relationships in the primate postcranium, and in fact, is uniquely situated to investigate intraspecific variability in the primate postcranium.

Bone has an ability to readjust its diaphyseal structure over the course of the lifetime of an animal (Currey, 2002; Martin et al., 1998). Cross-sectional geometric properties, as one means of quantifying in vivo adjustment, are frequently used in functional comparisons of human and non-human primate postcrania (Burr et al., 1982, 1989; Carlson, 2002, 2005; Carlson et al., 2006, in press; Demes and Jungers, 1989, 1993; Demes et al., 1991; Jungers et al., 1998, Ohman, 1993; Polk et al., 2000; Ruff, 1987, 1989, 2002; Ruff and Runestad, 1992; Schaffler et al., 1985; Stock and Pfeiffer, 2001; Sumner and Andriacchi, 1996; Sumner et al., 1989; Terranova, 1995a, b; Yamanaka et al., 2005). Efforts to quantify bone deformation during quadrupedal locomotion indicate the importance of using caution when inferring locomotor performance from crosssectional properties alone (Demes et al., 1998, 2001; Lieberman et al., 2004). For example, the common assumption that tissue economy in diaphyseal cross sections should be optimized for resisting the observed bending loads does not hold true (Demes et al., 1998, 2001; Pearson and Lieberman, 2004; Ruff et al., 2006). When comparing limb loading during terrestrial quadrupedal locomotion and select modes of a primate arboreal locomotor repertoire (i.e., vertical climbing, brachiation), the latter are characterized by relatively greater variation in load orientations (Demes et al., 2001; Swartz et al., 1989). When using additional, but indirect measures to infer limb loading, e.g., substrate reaction forces, kinematics, and second moments of area, during even more locomotor behaviors, variability in loading regimes seems even greater than currently appreciated (Carlson and Judex, 2007; Demes et al., 2006; Demes and Carlson, in review). In addition to activity-induced deformations, other non-mechanical factors, e.g., genetics, hormones, and age affect bone modeling/remodeling process, which potentially could 
affect cross-sectional geometric properties independent of activity patterns (Devlin and Lieberman, 2007; Martin et al., 1998; Robling et al., 2007; Turner et al., 2000; Wergedal et al., 2005; Xiong et al., 2006). Despite the list of limitations, cross-sectional geometric properties retain value to paleoanthropologists and physical anthropologists as tools for inferring locomotor repertoires when animals can not be observed visually, such as extinct taxa (Griffin, 2008; Holt, 2003; Madar et al., 2002; Marchi et al., 2006; Ruff, 2008).

Shape variation in select regions of African ape femoral and humeral diaphyses is associated with reported frequencies of arboreal locomotion (Carlson, 2002, 2005). More evenly distributed bone mass in a cross section (i.e., more circular shape) has been correlated with increased percentage of arboreal locomotion, while more elliptical cross sections have been correlated with increased percentage of terrestrial locomotion (Figure 1). Frequencies of specific locomotor behaviors in a behavioral repertoire, however, have not been linked to diaphyseal shapes in a similarly straightforward fashion, whether using a museum collection sample (Carlson, 2005) or a small sample of free-ranging chimpanzees (Carlson et al., 2006).

A comparison of Gombe, Mahale, and Taï chimpanzees tentatively linked differences in habitat characteristics between the three communities to structural differences in their diaphyseal morphology (Carlson et al., in press). A terrain effect observed in human lower limb structural properties (Ruff, 1999) also was visible in some chimpanzee populations apart from any differences in locomotor mode frequencies. Qualitative variation within a single locomotor mode, such as habitat-induced variation in quadrupedalism, ultimately could impact deformation patterns experienced by limb elements. Mobility (c.f., Carlson et al., 2007), which can be described as distance travelled plus the frequency of maneuvering around obstacles within a habitat, may reflect characters such as vegetation density or ground cover. Elevation changes 
and ruggedness of terrain are two additional factors that can distinguish habitats. Previous work has shown that mobility and terrain elevation/ruggedness are relevant to human patterns of lower limb loading (Burr et al., 1996; Ruff, 1999). Such scenarios remain to be verified in non-human primate populations, but would seem to be present given the conservative nature of bone response to loading among organisms (Martin et al., 1998; Currey, 2002).

With a unique sample of primates we overcome ordinary challenges that limit functional morphologists, and in a sense we bring the field into the laboratory. In order to reconfirm earlier proposed form-function relationships in the chimpanzee postcranium, we add individuals from a fourth well-studied chimpanzee community to a previous comparison of individuals from three chimpanzee communities (Carlson et al., in press). Do femoral and humeral diaphyseal shapes of Kibale chimpanzees differ from shapes at analogous diaphyseal locations of Gombe, Mahale, or Taï chimpanzees? Do 'strength' properties that estimate maximum bending rigidity distinguish Kibale chimpanzees from chimpanzees in the other communities? Do percent cortical areas (\%CA) distinguish Kibale chimpanzees from chimpanzees in the other communities? Do the observed morphological differences between Kibale chimpanzees and chimpanzees from other communities reinforce previous interpretations of morphological differences between Mahale, Gombe, and Taï chimpanzees that were attributed to habitat characteristics? Ultimately, if habitat characteristics can be used to differentiate loading patterns in human populations, they may similarly distinguish habituated chimpanzee communities, which would have important implications for reconstructing locomotor repertoires of early hominins.

\section{Materials and Methods}


In order to acquire cross-sectional geometric properties, we used serial computed tomography (CT) scans of humeri and femora representing 40 adult chimpanzees (Pan troglodytes) from Gombe (Tanzania), Kibale (Uganda), Mahale Mountains (Tanzania), and Taï Forest (Côte d'Ivoire) National Parks. The sample from Gombe, Mahale Mountains, and Taï Forest National Parks has been described previously (Carlson et al., 2006, in press). Wherever possible we collected bilateral data from forelimbs and hind limbs of an individual. For each bone, we analyzed three regions of interest (ROIs): 35 (mid-distal), 50 (midshaft), and 65 (midproximal) percent diaphyseal lengths (Table 1). We excluded individuals that exhibited serious injuries or disabling diseases that we thought could have permanently altered locomotor repertoires. We retained several Taï individuals in the sample that died as a result of an Ebola epidemic (Boesch and Boesch-Achermann, 2000), but because of the rapid onset of death associated with Ebola, we believe that individuals that died from an Ebola infection had insufficient time for any reduction in activity level to alter bone diaphyseal morphology significantly.

We followed an existing protocol for obtaining CT data from Kibale specimens (Carlson et al., 2006, in press). Briefly, we saved CT images in DICOM format. We imported DICOM stacks corresponding to entire long bones into commercial software, Amira ${ }^{\circledR} 4.0$ (Visage Imaging, Inc, Carlsbad, CA, USA), segmented DICOM stacks to create isosurfaces, and then rendered volumes of interest (VOIs) using thresholds that gave an accurate digital representation of bone surfaces. Selection of the appropriate threshold considered two criteria: eliminate artificial holes in surfaces and separate lower density objects, such as soft tissues, from bone surfaces. Variation in the appropriate thresholds for different bones was minor following these criteria. Once a VOI was rendered, it was aligned in virtual space using the same criteria as 
previous studies that aligned physical specimens in CT scanners (Carlson, 2005; Carlson et al., 2006, in press; Ruff, 2002). Subsequent to identifying ROIs, we used cutting planes in the commercial software to virtually section the rendered VOIs. We used screen capture software programs, or options within the visualization software program, to record digital images of virtually 'sectioned' surfaces. We calculated cross-sectional geometric properties of virtual 'sections' using custom-written macros for Scion Image (release Beta 4.0.2; ported from NIH Image for Macintosh by Scion Corporation and freely available at http://www.scioncorp.com) and a modified version of the SLICE program (Nagurka and Hayes, 1980).

The custom-written macro calculates standard cross-sectional geometric properties from a cross section, e.g., maximum rigidity $\left(I_{\max }\right)$. We treated cortical bone in cross sections as having homogeneous material properties, which is customary in analyses of cross-sectional properties (but see Bhatavadekar et al., 2006). We calculated shape ratios from principal moments of area $\left(\mathrm{I}_{\max } / \mathrm{I}_{\min }\right)$ rather than second moments of area about anatomical planes $\left(\mathrm{I}_{\mathrm{x}} / \mathrm{I}_{\mathrm{y}}\right)$ since the former ratio provides a more accurate reflection of overall shape (Carlson, 2005). We calculated percentage cortical area (\%CA) of cross sections as cortical area (CA) divided by total area (TA). Following Sumner et al. (1989), this measure provides a useful estimate of bone mass at a diaphyseal location.

When modeling bending deformation of a beam, bending is proportional to the product of the applied force and the length of the beam. When comparing a bone to a beam undergoing bending, body weight is a suitable substitute for applied force and bone length is a suitable substitute for the length of the beam. Chimpanzee body mass is known to vary according to several factors, including banana provisioning, community range size and density, seasonality, social rank in females, female reproductive cycles, and age (Pusey et al., 2005). Unfortunately, 
body mass was unknown for a vast majority of chimpanzees in the sample so we were forced to estimate it using osteological predictors. In order to estimate body mass for scaling femoral properties (see Eq. 1), we regressed body mass, bm, on supero-inferior diameter of the femoral head, fmsid (Ruff, 2002; Carlson et al., 2006). Carlson (2002) estimated body masses for 25 African apes of known body mass using Eq. 1 and found that $80 \%$ had predicted values within $20 \%$ of their recorded body mass. We estimated body mass for each right and left femur separately. We use femoral mechanical length in scaling measures since this is a suitable estimate for the length of the bone as it undergoes bending forces (Ruff, 2002; Carlson et al., 2006). We measure femoral mechanical length from each right and left femur separately in order to derive side-specific scaling factors. In order to compare individuals, we normalize $I_{\max }$ to the product of estimated body mass and bone length (Eq. 2), where s $I_{\max }=$ normalized $I_{\max }, \mathrm{bm}=$ body mass, and $\mathrm{L}=$ bone length.

$$
\begin{aligned}
\log _{10}(\mathrm{bm}) & =3.030\left(\log _{10} \mathrm{fmsid}\right)+(-2.946) \\
\mathrm{s} I_{\text {max }} & =I_{\max }((\mathrm{bm}) \mathrm{x}(\mathrm{L}))^{-1}
\end{aligned}
$$

In order to estimate body mass for scaling humeral properties (see Eq. 3), we regressed body mass on maximum diameter of the humeral head, hhmd (Carlson, 2002). Using Eq. 3, Carlson (2002) found that $87 \%$ of the 25 African apes had predicted body mass values within $20 \%$ of their recorded body mass. We estimated body mass for each right and left humerus separately. For humeral diaphyses, we use maximum length of the humerus with the long axis of the diaphysis parallel to the longitudinal axis (Carlson, 2002). We measured bone length from 
each right and left humerus separately in order to derive side-specific scaling factors for normalizing humeral $I_{\max }$ (Eq.2).

$$
\log _{10}(\mathrm{bm})=2.824\left(\log _{10} \mathrm{hhmd}\right)+(-2.896)
$$

We report habitat characteristics of Kibale National Park (Chapman et al., 1997; Hunt and McGrew, 2002) that are analogous to those reported in an earlier comparative study of chimpanzees from Gombe, Mahale Mountains, and Taï Forest National Parks (Carlson et al., in press), and when possible, we update values for previously reported characteristics. We concentrate on specific habitat characteristics that we believe introduce qualitative differences into terrestrial quadrupedalism, such as estimates of obstacle frequency during quadrupedalism and the extent of locomotion over uneven terrain (Table 2).

We used Kolmogorov-Smirnov (KS) tests for normality to assess variable distributions against to theoretical (normal) distributions. Since no variables departed significantly from normal distributions, parametric statistical analyses were justified. Accordingly, we used a series of one-way analyses of variance (ANOVA) to assess differences between Kibale, Gombe, Mahale, and Taï communities. In the event that groups differed significantly, we used a Levene test for homogeneity of variances to verify the assumption of equal group variances, which is a necessary assumption of the one-way ANOVA. The Levene test also dictated which post hoc analysis was used to determine which groups differed from one another. When we observed a non-significant Levene statistic, i.e., group variances did not significantly differ, we performed Bonferroni post hoc analyses. In comparisons where there were three groups or fewer, we used Fisher's least significant difference (LSD) post hoc analyses rather than Bonferroni post hoc 
analyses because the conservative Bonferroni correction for multiple comparisons was deemed too restrictive. When we observed a significant Levene statistic (i.e., group variances significantly differed), we conducted Tamhane's T2 post hoc analyses. A Tamhane's T2 post hoc analysis is based on a t-test, and is preferable to other alternatives because it is conservative. In comparisons of sex-specific community trends, where sample sizes were often small, e.g., $\mathrm{n}<$ 4, we frequently chose a more conservative approach than one-way ANOVA by using the Kruskal-Wallis $\mathrm{H}$ test, a non-parametric test. The Kruskal-Wallis $\mathrm{H}$ test is a one-way ANOVA that compares groups by ranking data and does not assume normality.

We selected $p<0.05$ as the level of statistical significance in all statistical testing. We used SPSS 15.0 software package (SPSS Inc., Chicago, IL, USA) for statistical procedures.

\section{Results}

Kibale chimpanzees versus other community chimpanzees

Average shape ratios at diaphyseal ROIs for the four chimpanzee communities are reported in Table 3. Kibale chimpanzees exhibit significantly lower shape ratios than Taï chimpanzees at several locations: right F35 and F50 ROIs, as well as the right H50 ROI (Table 4). Kibale chimpanzees have significantly higher shape ratios than either Taï or Mahale chimpanzees at the right $\mathrm{H} 35 \mathrm{ROI}$, and significantly higher shape ratios than Taï chimpanzees at the left H35 ROI (Table 4). While right humeri and femora from Gombe individuals were unavailable for comparisons, at the left H50 ROI, Kibale chimpanzees exhibited significantly higher shape ratios than Gombe chimpanzees.

Average maximum rigidities at diaphyseal ROIs are reported in Table 3. Normalizing measures are available for only a subset of the communities, which means that not all four 
communities could be compared. Taï chimpanzees exhibit significantly greater normalized maximum rigidity than Kibale and Mahale chimpanzees at right F50 and F65 ROIs, and greater normalized maximum rigidity than Mahale chimpanzees at the right F35 ROI (Table 4). No significant community-level differences are observed at ROIs of the left femur or either humerus. Average \%CAs at diaphyseal ROIs for the four chimpanzee communities are reported in Table 3. Kibale chimpanzees do not differ significantly from Mahale or Taï chimpanzees at any femoral or humeral ROI. Kibale chimpanzees, similar to Mahale and Taï chimpanzees, have significantly higher \%CA than Gombe chimpanzees at each left humeral ROI. Amongst femoral ROIs, Kibale chimpanzees exhibit significantly higher \%CAs than Gombe chimpanzees at the left F65 ROI, while Mahale and Taï chimpanzees exhibit significantly higher \%CAs than Gombe chimpanzees at left F50 and F65 ROIs. No significant community-wide differences in \%CA were observed in right elements, for which Gombe individuals were not included. This is consistent with left ROIs, where the only significant differences in \%CA rest between individuals in the Gombe community and individuals in the other three communities.

$\underline{\text { Sex-specific comparisons of Kibale chimpanzees with chimpanzees in other communities }}$

In order to examine community-level comparisons more in-depth, average shape ratios and $\% \mathrm{CAs}$ for females and males in the communities are reported in Table 5. Female chimpanzees from Kibale exhibit significantly greater shape ratios than Taï chimpanzees at left and right H35 ROIs (Table 6). Female Kibale chimpanzees also exhibit significantly lower shape ratios than Taï chimpanzees at the right H50 ROI (Table 6). Female chimpanzees from Kibale, Mahale, and Taï communities exhibit significantly greater \%CA at each humeral ROI compared to female chimpanzees from Gombe (Table 7). Unlike Mahale and Taï female 
chimpanzees, female chimpanzees from Kibale do not differ from female chimpanzees from Gombe in \%CA at femoral ROIs (Table 7). Compared to female chimpanzees from all communities, female chimpanzees from Kibale differ least in average shape ratios or \%CAs from Mahale females. Males from each of the four communities do not differ significantly in shape ratio or \%CA at any femoral or humeral ROI.

Average normalized maximum rigidities are reported for females and males in Table 8. Normalizing measures are available for only a subset of the communities, which means that not all four communities can be compared. Female chimpanzees from Taï exhibit significantly greater normalized maximum rigidity than female chimpanzees from Kibale at left $\mathrm{H} 50$ and $\mathrm{H} 65$ ROIs (Table 9). In a smaller sample of right humeri, the difference in normalized maximum rigidity between females from these two communities approaches statistical significance $(p=$ 0.064) at each ROI. Male chimpanzees from Kibale, Mahale, and Taï communities do not differ significantly from one another in normalized maximum rigidity at any femoral or humeral ROI.

\section{$\underline{\text { Ranks of community structural properties vs. habitat differences }}$}

In order to assess one aspect of mobility, Carlson et al. (in press) used average annual rainfall and ground cover to estimate the density of obstacles, e.g., trees, in the habitats of Gombe, Mahale, and Taï chimpanzees. Taï Forest National Park was estimated to have the highest prevalence of obstacles, and chimpanzees from Taï often had higher shape ratios than chimpanzees from Gombe or Mahale (Carlson et al., in press). Extending the comparison to include Kibale chimpanzees indicates that Kibale has the lowest average annual rainfall of the four communities, and presumably exceeds only Gombe in ground cover according to qualitative estimates (Table 10). Kibale chimpanzees, however, appear not to fit the proposed trend 
(Carlson et al., in press) since they frequently have the highest or second highest shape ratio to Taï chimpanzees at each of the ROIs.

In order to assess a second aspect of mobility, Carlson et al. (in press) used elevation range and slope of terrain to estimate terrain elevation/ruggedness in the habitats of Gombe, Mahale, and Taï chimpanzees. Kibale National Park outranks Taï Forest National Park in these measures of habitat complexity, but falls below reported estimates from Gombe and Mahale. Kibale shape ratios at femoral and humeral ROIs, particularly at the former diaphysis, usually exceed those of Gombe and Mahale individuals (Table 10). In other words, diaphyses of Kibale chimpanzees usually are less circular than chimpanzees from Gombe and Mahale, but more circular than chimpanzees from Taï. This supports the trend between terrain elevation/ruggedness and diaphyseal shape that was noted by Carlson et al. (in press).

\section{Discussion}

Communities differ significantly in shape at a majority of femoral and humeral diaphyseal locations. Kibale individuals differ specifically from Taï individuals at several locations, but except for the right humeral mid-distal diaphysis (H35) and the left humeral midshaft (H50), Kibale individuals do not differ significantly from Mahale or Gombe individuals at any location. Thus, addition of a fourth chimpanzee community to an earlier comparison of several chimpanzee communities that reported significantly greater shape ratios, i.e., more elliptical diaphyses, in Taï chimpanzees compared to other chimpanzees (Carlson et al., in press) largely reinforces the same pattern; Taï chimpanzees, particularly females, tend to exhibit distinct diaphyseal shapes. Since diaphyseal circularity (e.g., more evenly distributed bone mass in multiple directions) is a stable structural solution in the face of multi-directional deformations 
(Biewener, 2003), which according to a limited body of data (Swartz et al., 1989; Demes et al., 2001; Demes and Carlson, in press) probably characterize arboreal locomotor behaviors compared to terrestrial locomotor behaviors, it is uncertain why Taï individuals exhibit more elliptical femoral diaphyses even after adding individuals from a fourth community (Kibale) to comparisons.

One possible explanation proposed by Carlson et al. (in press) focused on the fact that chimpanzees tend to exhibit greater ML rigidity relative to AP rigidity throughout the femoral diaphysis, with a less consistent disparity present in the humeral diaphysis (Carlson, 2002, 2005). In addition to potential community-level differences between the percentage of locomotion in arboreal and terrestrial settings, qualitative differences within terrestrial quadrupedalism at the communities might be possible to infer if morphological trends are assessed in the context of ecological trends. Based on the effect that changes in direction have on mediolateral external forces (Demes et al., 2006) and bony morphology (Carlson and Judex, 2007), Carlson et al. (in press) proposed that chimpanzees occupying more densely forested habitats may experience greater side-to-side forces during terrestrial quadrupedalism compared to chimpanzees occupying less densely forested habitats, which may further enhance the disparity between ML rigidity and AP rigidity in diaphyseal cross sections. The ultimate result in this case could be more elliptical diaphyses in chimpanzees inhabiting denser forested habitats. The inclusion of Kibale chimpanzees in the comparison of chimpanzee communities does not support this possibility in a straightforward manner. The forest at Kibale is comparatively more 'open' than Tai and probably at least as open, if not more, than the forests at Gombe and Mahale according to estimates of average annual rainfall and descriptions of ground cover (Table 10). Yet, Kibale chimpanzees tended to possess more elliptical diaphyses than Gombe and Mahale chimpanzees, 
and occasionally more elliptical diaphyses than Taï chimpanzees. Additional comparative research is necessary to assess whether this ecomorphological relationship can be observed in free-ranging chimpanzees.

The descriptions of forests at each of the four communities as more or less dense likely oversimplify complexity in forest structure. Densities of forest canopy and forest understory often are inversely related because the former can directly affect the amount of sunlight that is available to the latter (Gentry and Emmons, 1987; Montgomery and Chazdon, 2001; Dial et al., 2004). Furthermore, forest understory can be a complex relationship between palm cover and small sapling cover (Harms et al., 2004), each of which may present different challenges to maneuvering through the understory. Thus, when considering a forest with more 'closed' canopy conditions, e.g., Taï, versus a forest with more 'open’ canopy conditions, e.g., Gombe, the understory conditions may be variable as well. In forests characterized by a dense understory, game trails and man-made transects cleared of vegetation, e.g., as can exist at habituated sites, may serve as alternate travel routes that would avoid much of the side-to-side terrestrial maneuvering that would be necessary in their absence. The frequency of maneuvering around obstacles during terrestrial quadrupedalism may not be easily predicted from simple measures of the degree to which the canopy is 'open' versus 'closed'. Further work towards identifying ecological variables that could be better estimators of maneuverability and quantifying the extent of maneuverability itself would be useful.

After adding Kibale chimpanzees to a previous comparisons of free-ranging chimpanzees (Carlson et al., in press), Mahale chimpanzees exhibit the lowest or next to lowest average shape ratios in femoral and humeral ROIs, except amongst left humeral mid-distal diaphyses (H35) of females. Mahale is characterized by the greatest range of elevations compared to the other three 
communities, while Kibale exceeds only Taï (Table 10). Since chimpanzees generally have greater ML rigidity than AP rigidity at diaphyseal ROIs, particularly in the femur (Carlson, 2002; Carlson et al., 2006), Carlson et al. (in press) suggested that an increase in circularity of Mahale femoral diaphyses is consistent with increased AP rigidity relative to ML rigidity. The addition of chimpanzees from a fourth habitat, Kibale, to this comparison reinforces the possibility for a terrain effect exhibited in chimpanzees long bone diaphyseal structure. The broadening of the comparison to four chimpanzee communities reinforces the potential for a terrain effect in chimpanzees, which would appear to parallel a similar terrain effect reported in humans (Ruff, 1999).

In comparing \%CA at diaphyseal ROIs from chimpanzees of all four communities, i.e., left elements only, Kibale chimpanzees exhibit greater \%CA than Gombe chimpanzees at four of the six ROIs. As noted in an earlier study (Carlson et al., in press), Mahale and Taï chimpanzees exhibit greater \%CA than Gombe individuals at five of these same ROIs (Table 4). In present comparisons, Kibale chimpanzees appear similar to Mahale and Taï chimpanzees. The similarity between individuals from Kibale, Mahale, and Taï communities is illustrated further by comparing \%CA in right diaphyses, where no significant group differences were observed after removing Gombe individuals from the comparisons (Table 4). Reduced \%CA in concert with diaphyseal shape change is helpful for identifying reduced functional loading in the limbs (Carlson et al., in press). Reduced functional loading of the limbs is likely a result of the alterations observed in chimpanzee locomotor repertoires with advancing age (Goodall, 1986; Morbeck et al., 2002). Average ages for chimpanzees in the samples from Gombe, Mahale, and Tai are 33.3, 30.1, and 25.0 years, respectively (Carlson et al., in press). Unfortunately precise age estimates for Kibale chimpanzees are unavailable (Carter et al., 2008). Based on the 
combination of trends in shape ratio and \%CA comparisons, it is likely that the chimpanzees comprising the Kibale sample had not experienced an age-induced reduction in activity levels, such as what seems to characterize many of the individuals comprising the Gombe sample.

Finally, overall similarity in structural properties of the chimpanzee femoral and humeral diaphyses between Kibale and Mahale chimpanzees, versus the relatively distinctive position of Taï chimpanzees among the four communities parallels current notions of genetic relatedness between chimpanzees in the four communities. The western chimpanzee (P. t. verus) diverged from the more closely related central and eastern chimpanzees (P. t. schweinfurthii) approximately 0.84 million years ago (Becquet et al., 2007). Clearly, however, genes are not the only contributing factor to variation in diaphyseal structural properties in the sample. Assessing cross-sectional geometric properties of the limb diaphyses of additional western chimpanzee populations would be interesting in this regard. In addition, incorporating additional populations that would expand the range of habitats to include more extreme conditions such as dry, open habitats (e.g., Toro-Semliki Wildlife Reserve, Uganda) would be equally useful.

\section{Acknowledgements}

We are grateful to the L.S.B. Leakey Foundation for financially supporting this research. We acknowledge and thank the cooperation of the government of Uganda, the Uganda National Council for Science and Technology, the Uganda Wildlife Authority, and Makerere University. We wish to thank in particular, Dr. John Kasenene for facilitating access to the Kibale chimpanzee skeletal material. We also thank the Field Museum of Natural History for allowing access to specimens in their care. We thank Bill Stanley and Lawrence Heaney for their assistance during the work conducted at the Field Museum. We thank the Kampala Imaging 
Centre for permitting use of their CT scanner in Kampala, and Craig Wambura for his assistance in scanning specimens. We thank Rush University Medical Center, Department of Radiology for permitting use of their CT scanner in Chicago, and Chris Archer and Edward Jones for their assistance in scanning specimens. We also thank the Institut für Radiologie, Kantonspital, Winterthur and the Universitätspital, Zürich for permitting the use of their CT scanners. Isuf Hoxha and Michael Krupa provided critical assistance with scanning specimens in Zürich. We also wish to thank David Burr, Diane Doran-Sheehy, Jane Goodall, Harumoto Gunji, Kevin Hunt, and Tanya Smith for their assistance at various times during this research. Luci-Betti Nash kindly provided her artistic skill in composing Figure 1. 


\section{References}

Becquet, C., Patterson, N., Stone, A.C., Przeworksi, M., \& Reich, D. (2007). Genetic structure of chimpanzee populations. PLoS Genetics, 3, e66.

Bhatavadekar, N. B., Daegling, D. J., and Rapoff, A. J. (2006). Application of an imagebased weighted measure of skeletal loading stiffness to great ape mandibles. Am. J. Phys. Anthropol. 131: 243-251.

Biewener, A.A. (2003). Animal Locomotion. Oxford University Press, Oxford.

Boesch, C., and Boesch-Achermann, H. (2000). The Chimpanzees of the Taï ForestBehavioural Ecology and Evolution. Oxford University Press, New York.

Burr, D.B., Milgrom, C., Fyhrie, D., Forwood, M., Nyska, M., Finestone, A., Hoshaw, S., Saiag, E., and Simkin, A. (1996). In vivo measurement of human tibial strains during vigorous activity. Bone 18: 405-410.

Burr, D.B., Piotrowski, G., Martin, R.B., and Cook, P.N. (1982). Femoral mechanics in the lesser bushbaby (Galago senegalensis): structural adaptations to leaping in primates. Anat. Rec. 202: 419-429.

Burr, D.B., Ruff, C.B., and Johnson, C. (1989). Structural adaptations of the femur and humerus to arboreal and terrestrial environments in three species of macaque. Am. J. Phys. Anthropol. 79: 357-367.

Carlson, K.J. (2002). Shape and material properties of African pongid femora and humeri: their relationship to observed positional behaviors. $\mathrm{PhD}$ thesis, Indiana University, Bloomington. 
Carlson, K.J. (2005). Investigating the form-function interface in African apes relationships between principal moments of area and positional behaviors in femoral and humeral diaphyses. Am. J. Phys. Anthropol. 127: 312-334.

Carlson, K.J., Demes, B., and Franz, T. (2005). Mediolateral forces associated with quadrupedal gaits of lemurids. J. Zool. (Lond.) 266: 261-273.

Carlson, K.J., Doran-Sheehy, D.M., Hunt, K.D., Nishida, T., Yamanaka, A., and Boesch, C. (2006). Locomotor behavior and long bone morphology in individual freeranging chimpanzees. J. hum. Evol. 50: 394-404.

Carlson, K.J., Grine, F.E., and Pearson, O.M. (2007). Robusticity and sexual dimorphism in the postcranium of modern hunter-gatherers from Australia. Am. J. Phys. Anthropol. 134: 9-23.

Carlson, K.J., and Judex, S. (2007). Increased non-linear locomotion alters diaphyseal bone shape. J. Exp. Biol. 210: 3117-3125.

Carlson, K.J., Sumner, D.R., Morbeck, M.E., Nishida, T., Yamanaka, A., and Boesch, C. (in press). The role of non-behavioral factors in adjusting long bone diaphyseal structure in free-ranging chimpanzees. Int. J. Primatol. xx: x-x.

Carter, M.L., Pontzer, H., Wrangham, R.W., and Kerbis Peterhans, J. (2008). Skeletal pathology in Pan troglodytes schweinfurthii in Kibale National Park, Uganda. Am J. Phys. Anthropol. 135: 389-403.

Chapman, C.A., Chapman, L.J., Wrangham, R., Isabirye-Basuta, G., and Ben-David, K. (1997). Spatial and temporal variability in the structure of a tropical forest. Afr. J. Ecol. 35: 287-302. 
Currey, J.D. (2002). Bones: structure and mechanics. Princeton University Press, Princeton.

Demes, B., Carlson, K.J., and Franz, T.M. (2006). Cutting corners: the dynamics of turning behaviors in two primate species. J. Exp. Biol. 209: 927-937.

Demes, B., and Carlson, K.J. (in review). Locomotor variation and bending regimes of capuchin limb bones. Am. J. Phys. Anthropol. xxx: x-x.

Demes, B., and Jungers, W.L. (1989). Functional differentiation of long bones in Lorises. Folia Primatol. (Basel) 52: 58-69.

Demes, B., and Jungers, W.L. (1993). Long bone cross-sectional dimensions, locomotor adaptations and body size in prosimian primates. J. Hum. Evol. 25: 57-74.

Demes, B., Jungers, W.L., and Selpien, K. (1991). Body size, locomotion, and long bone cross-sectional geometry in Indriid primates. Am. J. Phys. Anthropol. 86: 537547.

Demes, B., Qin, Y., Stern, J.T., Jr., Larson, S.G., and Rubin, C.T. (2001). Patterns of strain in the Macaque tibia during functional activity. Am. J. Phys. Anthropol. 116: $257-265$.

Demes, B., Stern, J.T., Hausman, M.R., Larson, S.G., McLeod, K.J., and Rubin, C.T. (1998). Patterns of strain in the Macaque ulna during functional activity. Am. J. Phys. Anthropol. 106: 87-100.

Devlin, M.J., Lieberman, D.E. (2007). Variation in estradiol level affects cortical bone growth in response to mechanical loading in sheep. J. Exp. Biol. 210: 602-613. 
Dial, R., Bloodworth, B., Lee, A., Boyne, P., and Heys, J. (2004). The distribution of free space and its relation to canopy composition at six forest sites. Forest Science 50: $312-325$.

Goodall, J. (1986). The Chimpanzees of Gombe. The Belknap Press of Harvard University Press, Cambridge, MA.

Gentry, A.H. and Emmons, L.H. (1987). Geographical variation in fertility, phenology, and composition of the understory of Neotropical forests. Biotropica 19: 216-227.

Green, D.J., Gordon, A.D., and Richmond, B.G. (2007). Limb-size proportions in Australopithecus afarensis and Australopithecus africanus. J. hum. Evol. 52: 187200.

Griffin, N.L. (2008). Bone architecture of the hominin second proximal pedal phalanx: a preliminary investigation. J. hum. Evol. 54: 162-168.

Haeusler, M. and McHenry, H.M. (2007). Evolutionary reversals of limb proportions in early hominids? Evidence from KNM-ER 3735 (Homo habilis). J. hum. Evol. 53: $383-405$.

Harms, K.E., Powers, J.S., and Montgomery, R.A. (2004). Variation in small sapling density, understory cover, and resource availability in four Neotropical forests. Biotropica 36:40-51.

Holt, B. (2003). Mobility in Upper Paleolithic and Mesolithic Europe: evidence from the lower limb. Am. J. Phys. Anthropol. 122: 200-215.

Hunt, K.D. (1992). Positional behavior of Pan troglodytes in the Mahale Mountains and Gombe Stream National Parks, Tanzania. Am. J. Phys. Anthropol. 87: 83-105. 
Hunt, K.D., Cant, J.G.H., Gebo, D.L., Rose, M.D., and Walker, S.E. (1996). Standardized descriptions of primate locomotor and postural modes. Primates 37: 363-387.

Hunt, K.D., and McGrew, W.C. (2002). Chimpanzees in the dry habitats of Assirik, Senegal and Semliki Wildlife Reserve, Uganda. In Boesch, C., Hohmann, G., and Marchant, L.F. (eds.), Behavioural Diversity in Chimpanzees and Bonobos. Cambridge University Press, Cambridge, UK, pp. 35-51.

Jungers, W.L., Burr, D.B., and Cole, M.S. (1998). Body size and scaling of long bone geometry, bone strength, and positional behavior in cercopithecoid primates. In Strasser, E., Fleagle, J., Rosenberger, A., and McHenry, H.M. (eds.), Primate Locomotion - Recent Advances. Plenum Press, New York, pp. 309-330.

Lieberman, D.E., Polk, J.D., and Demes, B. (2004). Predicting long bone loading from cross-sectional geometry. Am. J. Phys. Anthropol. 123: 156-171.

Madar, S.I., Rose, M.D., Kelley, J., MacLatchy, L., Pilbeam, D. (2002). New Sivapithecus postcranial specimens from the Siwaliks of Pakistan. J. hum. Evol. 42: 705-752.

Marchi, D. (2007). Relative strength of the tibia and fibula and locomotor behavior in hominoids. J. hum. Evol. 53: 647-655.

Marchi, D., Sparacello, V.S., Holt, B.M., and Formicola, V. (2006). Biomechanical approach to the reconstruction of activity patterns in Neolithic Western Liguria, Italy. Am. J. Phys. Anthropol. 131: 447-455.

Martin, R.B., Burr, D.B., and Sharkey, N.A. (1998). Skeletal tissue mechanics. SpringerVerlag, New York. 
Montgomery, R.A., and Chazdon, R.L. (2001). Forest structure, canopy architecture, and light transmittance in tropical wet forests. Ecology 82: 2707-2718.

Morbeck, M.E. (1999). Life history of Gombe chimpanzees: the inside view from the skeleton. In Strum, S.C., Lindburg, D.G., and Hamburg, D. (eds.), The New Physical Anthropology: science, humanism, and critical reflection. Prentice-Hall, Upper Saddle River, NJ, pp. 18-31.

Morbeck, M.E., Galloway, A., and Sumner, D.R. (2002). Getting old at Gombe: skeletal aging in wild-ranging chimpanzees. In Erwin, J., and Hof, P.R. (eds.), Aging in Nonhuman Primates. Interdisciplinary Topics in Gerontology, Vol. 31. Karger, Basel/New York, pp. 48-62.

Morbeck, M.E., Zihlman, A.L., Sumner, D.R., and Galloway, A. (1991). Poliomyelitis and skeletal asymmetry in Gombe chimpanzees. Primates 32: 77-91.

Nagurka, M.L., and Hayes, W.C. (1980). An interactive graphics package for calculating cross-sectional properties of complex shapes. J. Biomech. 13: 59-64.

Nishida, T. (ed.) (1990). The chimpanzees of the Mahale Mountains - sexual and life history strategies. University of Tokyo Press, Tokyo.

Ohman, J.C. (1993). Cross-sectional geometric properties from biplanar radiographs and computed tomography: functional application to the humerus and femur in hominoids. PhD thesis, Kent State University, Kent, OH, USA.

Pearson, O.M., and Lieberman, D.E. (2004). The aging of Wolff's "Law": ontogeny and responses to mechanical loading in cortical bone. Yrbk. Phys. Anthropol. 47: 6399. 
Polk, J.D., Demes, B., Jungers, W.L., Biknevicius, A.R., Heinrich, R.E., and Runestad, J.A. (2000). A comparison of primate, carnivoran and rodent limb bone crosssectional properties: are primates really unique? J. hum. Evol. 39: 297-325.

Pusey, A.E., Oehlert, G.W., Williams, J.M., and Goodall, J. (2005). Influences of ecological and social factors on body mass of wild chimpanzees. Int. J. Primatol. 26: $3-31$.

Robling, A.G., Warden, S.J., Shultz, K.L., Beamer, W.G., and Turner, C.H. (2007). Genetic effects on bone mechanotransduction in congenic mice harboring bone size and strength quantitative trait loci. J. Bone. Miner. Res. 22: 984-991.

Ruff, C.B. (1987). Structural allometry of the femur and tibia in Hominoidea and Macaca. Folia Primatol. (Basel) 48: 9-49.

Ruff, C.B. (1989). New approaches to structural evolution of limb bones in primates. Folia Primatol. (Basel) 53: 142-159.

Ruff, C.B. (1999). Skeletal structure and behavioral patterns of prehistoric Great Basin populations. In Hemphill, B.E., and Larsen, C.S. (eds.), Prehistoric Lifeways in the Great Basin Wetlands: Bioarchaeological Reconstruction and Interpretation. University of Utah Press, Salt Lake City, pp. 290-320.

Ruff, C.B. (2002). Long bone articular and diaphyseal structure in Old World monkeys and apes. I: Locomotor effects. Am. J. Phys. Anthropol. 119: 305-342.

Ruff, C.B. (2008). Femoral/humeral strength in early African Homo erectus. J. hum. Evol. 54: 383-390. 
Ruff, C.B., Holt, B., and Trinkaus, E. (2006). Who's afraid of the big bad Wolff?:

“Wolff's Law" and bone functional adaptation. Am. J. Phys. Anthropol. 129: 484498.

Ruff, C.B., and Runestad, J.A. (1992). Primate limb bone structural adaptations. Annu. Rev. Anthropol. 21: 407-433.

Schaffler, M.B., Burr, D.B., Jungers, W.L., and Ruff, C.B. (1985). Structural and mechanical indicators of limb specialization in primates. Folia Primatol. (Basel) 45: 61-75.

Stock J., and Pfeiffer, S. (2001). Linking structural variability in long bone diaphyses to habitual behaviors: foragers from southern African Later Stone Age and Andaman Islands. Am. J. Phys. Anthropol. 115:337-348.

Sumner, D.R., and Andriacchi, T.P. (1996). Adaptation to differential loading: comparison of growth-related changes in cross-sectional properties of the human femur and humerus. Bone 19:121-126.

Sumner, D.R., Morbeck, M.E., and Lobick, J.J. (1989). Apparent age-related bone loss among adult female Gombe chimpanzees. Am. J. Phys. Anthropol. 79: 225-234.

Swartz, S.M., Bertram, J.E.A., and Biewener, A.A. (1989). Telemetered in vivo strain analysis of locomotor mechanics of brachiating gibbons. Nature 342: 270-272

Terranova, C.J. (1995a). Functional morphology of leaping behaviors in galagids: associations between loading, limb use and diaphyseal geometry. In Atterman, L., Izard, M.K., and Doyle, G.A. (eds.). Creatures of the dark: the nocturnal prosimians. Plenum Press, New York, pp. 473-493. 
Terranova, C.J. (1995b). Leaping behaviors and the functional morphology of strepsirhine primate long bones. Folia Primatol. (Basel) 65: 181-201.

Turner, C.H., Hsieh, Y.F., Muller, R., Bouxsein, M.L., Baylink, D.J., Rosen, C.J., Grynpas, M.D., Donahue, L.R., and Beamer, W.G. (2000). Genetic regulation of cortical and trabecular bone strength and microstructure in inbred strains of mice. J. Bone Miner. Res. 15: 1126-1131.

Wergedal, J.E., Sheng, M.H., Ackert-Bicknell, C.L., Beamer, W.G., and Baylink, D.J. (2005). Genetic variation in femur extrinsic strength in 29 different inbred strains of mice is dependent on variations in femur cross-sectional geometry and bone density. Bone 36: 111-122.

Xiong, D.H., Shen, H., Xiao, P., Guo, Y.F., Long, J.R., Zhao, L.J., Liu, Y.Z., Deng, H.Y., Li, J.L., Recker, R.R., and Deng, H.W. (2006). Genome-wide scan identified QTLs underlying femoral neck cross-sectional geometry that are novel studied risk factors of osteoporosis. J. Bone Miner. Res. 21: 424-437.

Yamanaka, A., Gunji, H., and Ishida, H. (2005). Curvature, Length, and Cross-sectional Geometry of the Femur and Humerus in Anthropoid Primates. Am. J. Phys. Anthropol. 127: 46-57. 


\section{Figure caption}

Figure 1. Theoretical expectations for shape ratios of individuals occupying more closed

habitat conditions, performing greater percentages of arboreal locomotion (top row), and individuals occupying more open habitat conditions, performing lesser percentages of arboreal locomotion (bottom row). 
Table 1 . Specimens comprising community samples.

\begin{tabular}{|c|c|c|c|c|}
\hline & Females & Males & Unknown & Represented elements \\
\hline Gombe $^{1}$ & 5 & 4 & & $\begin{array}{l}7 \text { left femora } \\
9 \text { left humeri }\end{array}$ \\
\hline Kibale & 4 & 6 & 1 & $\begin{array}{l}9 \text { bilateral femora, } 1 \text { left femur } \\
9 \text { bilateral humeri, } 2 \text { left humeri }\end{array}$ \\
\hline Mahale $^{1}$ & 3 & 1 & & $\begin{array}{l}4 \text { bilateral femora } \\
3 \text { bilateral humeri, } 1 \text { left humerus }\end{array}$ \\
\hline Taï ${ }^{1}$ & 10 & 5 & 1 & $\begin{array}{l}11 \text { bilateral femora, } 3 \text { left femur, } 1 \text { right femur } \\
11 \text { bilateral humeri, } 2 \text { left humeri }\end{array}$ \\
\hline \multicolumn{5}{|c|}{ 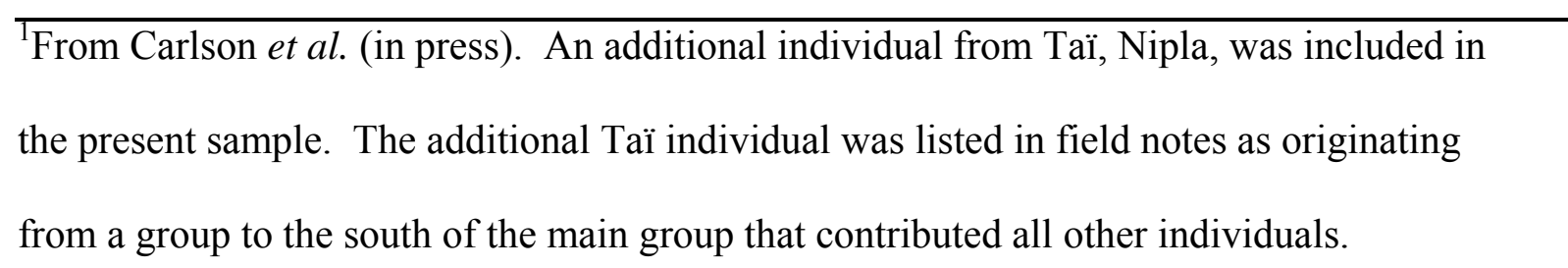 } \\
\hline \multicolumn{5}{|c|}{ However, since the habitat conditions for the added individual were likely more similar to } \\
\hline \multicolumn{5}{|c|}{ the habitat conditions for the other Taï chimpanzees relative to the habitat conditions for } \\
\hline chimpanze & in any $\mathrm{o}$ & other & ee commu & ties, it was reasonable to include this \\
\hline
\end{tabular}


Table 2. Habitat characteristics of habituated groups ${ }^{\mathrm{a}}$.

\begin{tabular}{|c|c|c|c|c|}
\hline & Gombe & Kibale $^{b}$ & Mahale & Taï \\
\hline Annual mean rainfall & $1775 \mathrm{~mm}$ & $1671 \mathrm{~mm}$ & $1836 \mathrm{~mm}$ & $1829 \mathrm{~mm}$ \\
\hline Ground cover & more open woodland & evergreen moist forest & M-group: closed forest, vine tangles & tropical moist forest \\
\hline Elevation range (above sea level) & $772-1500 \mathrm{~m}$ & $1000-1700 \mathrm{~m}$ & $772-2462 \mathrm{~m}$ & about $120 \mathrm{~m}$ \\
\hline Slope of terrain & 16.5 degrees & 6.8 degrees & 8.3 degrees & slightly undulating \\
\hline
\end{tabular}

${ }^{\mathrm{a}}$ Data sources described in Carlson et al. (in press), except annual mean rainfall data which has been updated to reflect data reported

by Hunt and McGrew (2002). Hunt and McGrew (2002) broadly compare ecological parameters (e.g., annual mean rainfall) for numerous chimpanzee habitats, including but not limited to the four habitats in the present study. Ultimately, we report values provided by Hunt and McGrew (2002) rather than those in Carlson et al. (in press) because the former favor more general comparisons and applications. ${ }^{\mathrm{b}}$ Kibale values calculated from data reported in Chapman et al. (1997). Slope of terrain reported as the average of four study areas characterized as moderately undulating valleys. 
Table 3. Community means (1 s.d.) for shape ratios $\left(\mathrm{I}_{\max } / \mathrm{I}_{\min }\right), \%$ cortical area, and normalized $\mathrm{I}_{\max }\left(\mathrm{sI}_{\max }\right)$.

\begin{tabular}{|c|c|c|c|c|c|c|c|}
\hline ROI & Gombe (left) & Kibale (left) & Kibale (right) & Mahale (left) & Mahale (right) & Taï (left) & Taï (right) \\
\hline F35 shape & $(0.19)$ & $(0.12)$ & $(0.11)$ & $(0.05)$ & $(0.04)$ & $(0.08)$ & $(0.13)$ \\
\hline \multirow[t]{3}{*}{ F50 shape } & 1.44 & 1.37 & 1.33 & 1.30 & 1.35 & 1.49 & 1.56 \\
\hline & $(0.16)$ & $(0.15)$ & $(0.13)$ & $(0.08)$ & $(0.10)$ & $(0.08)$ & $(0.17)$ \\
\hline & 7 & 10 & 9 & 4 & 4 & 14 & 12 \\
\hline F65 shape & 7 & 10 & 9 & 4 & 4 & 14 & 12 \\
\hline \multirow[t]{3}{*}{ H35 shape } & 1.26 & 1.40 & 1.46 & 1.24 & 1.20 & 1.13 & 1.17 \\
\hline & $(0.10)$ & $(0.21)$ & $(0.22)$ & $(0.02)$ & $(0.03)$ & $(0.08)$ & $(0.10)$ \\
\hline & 9 & 11 & 9 & 4 & 3 & 13 & 11 \\
\hline \multirow[t]{2}{*}{ H50 shape } & 1.12 & 1.26 & 1.21 & 1.19 & 1.15 & 1.35 & 1.38 \\
\hline & $(0.05)$ & $(0.15)$ & $(0.13)$ & $(0.05)$ & $(0.02)$ & $(0.12)$ & $(0.11)$ \\
\hline H65 shape & 9 & 11 & 9 & 4 & 3 & 13 & 11 \\
\hline \multirow[t]{3}{*}{$\mathrm{F} 35 \% \mathrm{CA}$} & 50.1 & 59.4 & 59.3 & 65.3 & 64.5 & 61.4 & 60.6 \\
\hline & (11.9) & $(8.4)$ & $(7.4)$ & $(12.1)$ & (11.9) & $(6.0)$ & $(4.6)$ \\
\hline & 7 & 10 & 9 & 4 & 4 & 14 & 12 \\
\hline \multirow[t]{3}{*}{$\mathrm{F} 50 \% \mathrm{CA}$} & 53.0 & 65.2 & 64.9 & 72.2 & 71.2 & 67.2 & 66.8 \\
\hline & (12.4) & $(9.0)$ & $(8.7)$ & (13.1) & $(13.4)$ & $(5.7)$ & $(4.4)$ \\
\hline & 7 & 10 & 9 & 4 & 4 & 14 & 12 \\
\hline \multirow[t]{3}{*}{$\mathrm{F} 65 \% \mathrm{CA}$} & 52.3 & 66.6 & 66.9 & 73.5 & 73.0 & 68.8 & 68.5 \\
\hline & (12.2) & $(9.3)$ & $(10.3)$ & (15.7) & $(15.8)$ & $(6.3)$ & $(4.6)$ \\
\hline & 7 & 10 & 9 & 4 & 4 & 14 & 12 \\
\hline $\mathrm{H} 35 \% \mathrm{CA}$ & 51.5 & 65.3 & 67.6 & 69.5 & 67.1 & 64.4 & 65.2 \\
\hline
\end{tabular}




\begin{tabular}{|c|c|c|c|c|c|c|c|}
\hline & (13.8) & (7.3) & (5.8) & (13.9) & (15.9) & (8.1) & (7.1) \\
\hline & 9 & 11 & 9 & 4 & 3 & 13 & 11 \\
\hline \multirow[t]{3}{*}{$\mathrm{H} 50 \% \mathrm{CA}$} & 47.0 & 60.3 & 61.9 & 67.6 & 64.2 & 61.7 & 63.3 \\
\hline & (11.6) & (7.1) & (5.8) & (13.0) & $(15.2)$ & (5.8) & (4.3) \\
\hline & 9 & 11 & 9 & 4 & 3 & 13 & 11 \\
\hline \multirow[t]{3}{*}{$\mathrm{H} 65 \% \mathrm{CA}$} & 43.5 & 58.1 & 59.2 & 62.9 & 59.6 & 61.1 & 61.9 \\
\hline & (9.3) & (6.4) & (6.3) & (13.8) & $(16.5)$ & (7.3) & (6.1) \\
\hline & 9 & 11 & 9 & 4 & 3 & 13 & 11 \\
\hline \multirow[t]{3}{*}{$\mathrm{F} 35 \mathrm{sI}$ max } & - & 1.18 & 1.18 & 1.05 & 1.09 & 1.37 & 1.35 \\
\hline & & $(0.20)$ & $(0.18)$ & $(0.12)$ & $(0.10)$ & $(0.32)$ & $(0.16)$ \\
\hline & & 10 & 9 & 4 & 4 & 6 & 7 \\
\hline \multirow[t]{3}{*}{$\mathrm{F} 50 \mathrm{sI}_{\max }$} & - & 1.20 & 1.18 & 1.07 & 1.15 & 1.41 & 1.41 \\
\hline & & $(0.18)$ & $(0.16)$ & $(0.14)$ & $(0.14)$ & $(0.33)$ & $(0.16)$ \\
\hline & & 10 & 9 & 4 & 4 & 6 & 7 \\
\hline \multirow[t]{3}{*}{$\mathrm{F} 65 \mathrm{sI}$ max } & - & 1.22 & 1.21 & 1.12 & 1.14 & 1.34 & 1.37 \\
\hline & & $(0.20)$ & $(0.18)$ & $(0.14)$ & $(0.08)$ & $(0.24)$ & $(0.13)$ \\
\hline & & 10 & 9 & 4 & 4 & 6 & 7 \\
\hline \multirow[t]{3}{*}{$\mathrm{H} 35 \mathrm{sI}_{\max }$} & - & 0.77 & 0.79 & - & - & 0.78 & 0.78 \\
\hline & & $(0.15)$ & $(0.17)$ & & & $(0.09)$ & $(0.11)$ \\
\hline & & 11 & 9 & & & 7 & 5 \\
\hline \multirow[t]{3}{*}{$\mathrm{H} 50 \mathrm{sI}_{\max }$} & - & 0.83 & 0.81 & - & - & 0.94 & 0.95 \\
\hline & & $(0.12)$ & $(0.12)$ & & & $(0.18)$ & $(0.21)$ \\
\hline & & 11 & 9 & & & 7 & 5 \\
\hline \multirow[t]{3}{*}{$\mathrm{H} 65 \mathrm{sI}_{\max }$} & - & 0.85 & 0.85 & - & - & 0.95 & 0.93 \\
\hline & & $(0.13)$ & $(0.11)$ & & & $(0.18)$ & $(0.21)$ \\
\hline & & 11 & 9 & & & 7 & 5 \\
\hline
\end{tabular}

$\mathrm{F}=$ femur, $\mathrm{H}$ = humerus; 35 = mid-distal diaphysis, 50 = midshaft, 65 = mid-proximal diaphysis. Cells contain mean values and 1 standard deviation in parentheses. Rows represent values of shape $\left(\mathrm{I}_{\max } / \mathrm{I}_{\min }\right)$ or \%CA at a given ROI (e.g., F35). Gombe individuals are represented by left elements only. ${ }^{1}$ Gombe, Mahale, and Taï data from Carlson et al. (in press). 
Table 4. Community structural comparisons.

\begin{tabular}{|c|c|c|c|c|c|c|c|c|c|}
\hline $\mathbf{I}_{\max } / \mathbf{I}_{\min }$ & $\mathbf{n}$ & $\mathbf{F}$ & $p$ & $\begin{array}{c}\text { Bonferroni } \\
\text { post hoc analysis }\end{array}$ & $\mathbf{I}_{\max } / \mathbf{I}_{\min }$ & $\mathbf{n}$ & $\mathbf{F}$ & $p$ & $\begin{array}{c}\text { LSD } \\
\text { post hoc analysis }\end{array}$ \\
\hline left F35 & 35 & 3.560 & 0.025 & $\mathrm{~T}>\mathrm{M}$ & right F35 & 25 & 7.382 & 0.004 & $\mathrm{~T}>>\mathrm{M} ; \mathrm{T}>\mathrm{K}$ \\
\hline left F50 & 35 & 3.312 & 0.033 & none & right F50 & 25 & 6.901 & 0.005 & $\mathrm{~T}>>\mathrm{K} ; \mathrm{T}>\mathrm{M}$ \\
\hline left F65 & 35 & 0.047 & 0.986 & - & right F65 & 25 & 3.233 & 0.059 & - \\
\hline left $\mathrm{H} 35^{\mathrm{a}}$ & 37 & 8.250 & $<0.001$ & $\mathrm{~K}, \mathrm{M} \gg>\mathrm{T} ; \mathrm{G}>\mathrm{T}$ & right $\mathrm{H} 35$ & 23 & 9.244 & 0.001 & $\mathrm{~K}>>\mathrm{T} ; \mathrm{K}>\mathrm{M}$ \\
\hline left H50 & 37 & 8.066 & $<0.001$ & $\mathrm{~T}>>\mathrm{G} ; \mathrm{K}>\mathrm{G}$ & right $\mathrm{H} 50$ & 23 & 7.765 & 0.003 & $\mathrm{~T}>>\mathrm{K}, \mathrm{M}$ \\
\hline left $H 65^{a}$ & 37 & 4.175 & 0.013 & $\mathrm{~T}>>\mathrm{G}$ & right $\mathrm{H} 65^{\mathrm{a}}$ & 23 & 3.661 & 0.044 & $\mathrm{~T}>\mathrm{M}$ \\
\hline$\% \mathrm{CA}$ & & & & & $\% \mathrm{CA}$ & & & & \\
\hline left F35 & 35 & 3.405 & 0.030 & none & right $F 35^{\mathrm{a}}$ & 25 & 0.775 & 0.473 & - \\
\hline left F50 & 35 & 5.080 & 0.006 & $\mathrm{M}, \mathrm{T}>\mathrm{G}$ & right $\mathrm{F} 50^{\mathrm{a}}$ & 25 & 0.887 & 0.426 & - \\
\hline left F65 & 35 & 5.745 & 0.003 & $\mathrm{M}, \mathrm{T}>>\mathrm{G} ; \mathrm{K}>\mathrm{G}$ & right $\mathrm{F} 65^{\mathrm{a}}$ & 25 & 0.632 & 0.541 & - \\
\hline left H35 & 37 & 4.492 & 0.009 & $\mathrm{~K}, \mathrm{M}, \mathrm{T}>\mathrm{G}$ & right $\mathrm{H} 35^{\mathrm{a}}$ & 23 & 0.240 & 0.789 & - \\
\hline left H50 & 37 & 7.419 & 0.001 & $\mathrm{M}, \mathrm{T}>>\mathrm{G} ; \mathrm{K}>\mathrm{G}$ & right $\mathrm{H} 50^{\mathrm{a}}$ & 23 & 0.169 & 0.846 & - \\
\hline left H65 & 37 & 9.465 & $<0.001$ & $\mathrm{~K}, \mathrm{M}, \mathrm{T}>>\mathrm{G}$ & right $\mathrm{H} 65$ & 23 & 0.312 & 0.735 & - \\
\hline $\mathbf{S I}_{\max }^{b}$ & & & & & $\mathbf{S I}_{\max }{ }^{b}$ & & & & \\
\hline left F35 & 20 & 2.490 & 0.113 & - & right F35 & 20 & 3.614 & 0.049 & $\mathrm{~T}>\mathrm{M}$ \\
\hline left $\mathrm{F} 50^{\mathrm{a}}$ & 20 & 2.948 & 0.080 & - & right F50 & 20 & 5.710 & 0.013 & $\mathrm{~T} \gg>\mathrm{K} ; \mathrm{T}>\mathrm{M}$ \\
\hline left F65 & 20 & 1.521 & 0.247 & - & right F65 & 20 & 3.717 & 0.046 & $\mathrm{~T}>\mathrm{K}, \mathrm{M}$ \\
\hline left H35 & 18 & 0.007 & 0.937 & - & right $\mathrm{H} 35$ & 14 & 0.014 & 0.907 & - \\
\hline left H50 & 18 & 2.706 & 0.119 & - & right $\mathrm{H} 50$ & 14 & 2.656 & 0.129 & - \\
\hline left H65 & 18 & 1.846 & 0.193 & - & right $\mathrm{H} 65$ & 14 & 0.713 & 0.415 & - \\
\hline
\end{tabular}


$>: \mathrm{p}<0.05 ;>>: \mathrm{p}<0.01 ; \mathrm{G}=$ Gombe, $\mathrm{K}=$ Kibale, $\mathrm{M}=$ Mahale, $\mathrm{T}=$ Taï; $\mathrm{F}=$ femur, $\mathrm{H}=$ humerus; 35 $=$ mid-distal diaphysis, $50=$ midshaft, $65=$ mid-proximal diaphysis. ${ }^{\mathrm{a}}$ Failed a Levene test of homogeneity of variances, thus when ANOVA was significant a Tamhane's T2 post hoc analysis was conducted. ${ }^{b}$ Femoral comparisons exclude Gombe, while humeral comparisons exclude Gombe and Mahale because of unavailable data for the scaling measurements. 
Table 5. Sex-specific community means (1 s.d.) for shape ratios $\left(I_{\max } / I_{\min }\right)$ and \% cortical area.

\begin{tabular}{|c|c|c|c|c|c|c|c|}
\hline & Gombe (left) & Kibale (left) & Kibale (right) & $\begin{array}{c}\text { Females } \\
\text { Mahale (left) }\end{array}$ & Mahale (right) & Taï (left) & Taï (right) \\
\hline F35 shape & $(0.21)$ & $(0.07)$ & $(0.11)$ & $(0.05)$ & $(0.04)$ & $(0.09)$ & $(0.14)$ \\
\hline \multirow[t]{3}{*}{ F50 shape } & 1.45 & 1.45 & 1.47 & 1.29 & 1.33 & 1.47 & 1.53 \\
\hline & $(0.17)$ & $(0.12)$ & $(0.13)$ & $(0.09)$ & $(0.10)$ & $(0.09)$ & $(0.14)$ \\
\hline & 5 & 3 & 3 & 3 & 3 & 8 & 8 \\
\hline F65 shape & 5 & 3 & 3 & 3 & 3 & 8 & 8 \\
\hline \multirow[t]{3}{*}{ H35 shape } & 1.24 & 1.36 & 1.39 & 1.25 & 1.21 & 1.14 & 1.15 \\
\hline & $(0.09)$ & $(0.09)$ & $(0.09)$ & $(0.02)$ & $(0.04)$ & $(0.09)$ & $(0.09)$ \\
\hline & 5 & 4 & 2 & 3 & 2 & 9 & 8 \\
\hline \multirow[t]{2}{*}{ H50 shape } & 1.13 & 1.24 & 1.18 & 1.19 & 1.16 & 1.38 & 1.40 \\
\hline & $(0.07)$ & $(0.16)$ & $(0.20)$ & $(0.06)$ & $(0.01)$ & $(0.12)$ & $(0.09)$ \\
\hline \multirow[t]{3}{*}{$\mathrm{F} 35 \% \mathrm{CA}$} & 44.7 & 48.7 & 51.3 & 65.7 & 64.8 & 60.8 & 60.2 \\
\hline & $(7.6)$ & $(0.7)$ & $(2.9)$ & $(14.8)$ & $(14.6)$ & $(5.5)$ & $(5.2)$ \\
\hline & 5 & 2 & 2 & 3 & 3 & 8 & 8 \\
\hline \multirow[t]{3}{*}{$\mathrm{F} 50 \% \mathrm{CA}$} & 48.1 & 55.1 & 57.2 & 71.7 & 70.3 & 66.4 & 65.7 \\
\hline & $(9.8)$ & $(7.5)$ & $(9.7)$ & $(15.9)$ & $(16.3)$ & $(5.3)$ & $(4.8)$ \\
\hline & 5 & 2 & 2 & 3 & 3 & 8 & 8 \\
\hline \multirow[t]{3}{*}{ F65 \%CA } & 47.3 & 55.9 & 56.0 & 72.3 & 71.8 & 67.0 & 67.2 \\
\hline & $(9.1)$ & $(6.5)$ & $(8.9)$ & $(19.0)$ & (19.1) & $(5.3)$ & $(4.6)$ \\
\hline & 5 & 2 & 2 & 3 & 3 & 8 & 8 \\
\hline $\mathrm{H} 35 \% \mathrm{CA}$ & 42.3 & 60.8 & 66.7 & 67.9 & 63.2 & 63.8 & 64.3 \\
\hline
\end{tabular}




\begin{tabular}{|c|c|c|c|c|c|c|c|}
\hline & $(9.4)$ & $(9.2)$ & $(-)$ & $(16.6)$ & $(20.4)$ & $(8.3)$ & $(6.0)$ \\
\hline & 5 & 3 & 1 & 3 & 2 & 9 & 8 \\
\hline \multirow[t]{2}{*}{$\mathrm{H} 50 \% \mathrm{CA}$} & 39.9 & 54.6 & 56.6 & 67.0 & 61.6 & 60.9 & 62.8 \\
\hline & $(8.0)$ & $(6.6)$ & $(-)$ & $(15.8)$ & $(20.5)$ & $(6.3)$ & $(3.9)$ \\
\hline \multirow[t]{3}{*}{$\mathrm{H} 65 \% \mathrm{CA}$} & 37.9 & 54.5 & 56.3 & 63.3 & 58.8 & 60.8 & 61.9 \\
\hline & $(6.2)$ & $(3.4)$ & $(-)$ & $(16.8)$ & $(23.3)$ & (8.7) & $(6.4)$ \\
\hline & 5 & 3 & 1 & 3 & 2 & 9 & 8 \\
\hline \multirow[t]{3}{*}{ F35 shape } & 1.38 & 1.42 & 1.37 & 1.34 & 1.34 & 1.53 & 1.51 \\
\hline & $(0.17)$ & $(0.12)$ & $(0.06)$ & $(-)$ & $(-)$ & $(0.08)$ & $(0.14)$ \\
\hline & 2 & 6 & 5 & 1 & 1 & 5 & 3 \\
\hline \multirow[t]{2}{*}{ F50 shape } & 1.39 & 1.34 & 1.28 & 1.34 & 1.42 & 1.50 & 1.55 \\
\hline & $(0.16)$ & $(0.17)$ & $(0.06)$ & $(-)$ & $(-)$ & $(0.08)$ & $(0.23)$ \\
\hline \multirow[t]{3}{*}{ H35 shape } & 1.30 & 1.48 & 1.55 & 1.23 & 1.17 & 1.11 & 1.22 \\
\hline & $(0.12)$ & $(0.23)$ & $(0.20)$ & $(-)$ & $(-)$ & $(0.06)$ & $(0.17)$ \\
\hline & 4 & 6 & 6 & 1 & 1 & 3 & 2 \\
\hline \multirow[t]{3}{*}{ H50 shape } & 1.10 & 1.22 & 1.17 & 1.17 & 1.14 & 1.26 & 1.29 \\
\hline & $(0.02)$ & $(0.11)$ & $(0.07)$ & $(-)$ & $(-)$ & $(0.10)$ & $(0.17)$ \\
\hline & 4 & 6 & 6 & 1 & 1 & 3 & 2 \\
\hline \multirow[t]{3}{*}{ H65 shape } & 1.14 & 1.21 & 1.18 & 1.18 & 1.12 & 1.19 & 1.08 \\
\hline & $(0.05)$ & $(0.09)$ & $(0.07)$ & $(-)$ & $(-)$ & $(0.12)$ & $(0.05)$ \\
\hline & 4 & 6 & 6 & 1 & 1 & 3 & 2 \\
\hline \multirow[t]{2}{*}{$\mathrm{F} 35 \% \mathrm{CA}$} & 63.6 & 63.3 & 62.4 & 63.9 & 63.6 & 63.4 & 63.0 \\
\hline & $(10.7)$ & $(7.7)$ & $(6.1)$ & $(-)$ & $(-)$ & $(7.2)$ & $(2.3)$ \\
\hline
\end{tabular}




\begin{tabular}{|c|c|c|c|c|c|c|c|}
\hline & (10.6) & (6.9) & $(6.2)$ & $(-)$ & $(-)$ & (6.9) & (1.6) \\
\hline & 2 & 4 & 4 & 1 & 1 & 5 & 3 \\
\hline \multirow{3}{*}{$\mathrm{F} 65 \% \mathrm{CA}$} & 65.0 & 70.4 & 71.7 & 76.9 & 76.7 & 72.2 & 72.6 \\
\hline & (11.1) & $(6.2)$ & (6.0) & $(-)$ & $(-)$ & $(7.7)$ & $(3.2)$ \\
\hline & 2 & 4 & 4 & 1 & 1 & 5 & 3 \\
\hline \multirow[t]{3}{*}{$\mathrm{H} 35 \% \mathrm{CA}$} & 63.0 & 68.6 & 68.9 & 74.1 & 75.0 & 65.4 & 67.2 \\
\hline & (8.7) & $(4.2)$ & (4.8) & $(-)$ & $(-)$ & (10.4) & (15.4) \\
\hline & 4 & 4 & 4 & 1 & 1 & 3 & 2 \\
\hline \multirow[t]{3}{*}{$\mathrm{H} 50 \% \mathrm{CA}$} & 55.9 & 63.2 & 63.4 & 69.2 & 69.5 & 63.3 & 63.6 \\
\hline & (9.1) & (5.5) & (4.9) & $(-)$ & $(-)$ & (6.1) & $(8.2)$ \\
\hline & 4 & 4 & 4 & 1 & 1 & 3 & 2 \\
\hline \multirow{3}{*}{$\mathrm{H} 65 \% \mathrm{CA}$} & 50.4 & 60.5 & 60.7 & 61.6 & 61.2 & 60.6 & 59.1 \\
\hline & (8.1) & (8.1) & (7.4) & $(-)$ & $(-)$ & (3.7) & $(7.2)$ \\
\hline & 4 & 4 & 4 & 1 & 1 & 3 & 2 \\
\hline
\end{tabular}


Table 6. Community sex-specific comparisons in diaphyseal shape $\left(\mathrm{I}_{\max } / \mathrm{I}_{\min }\right)$

\begin{tabular}{|c|c|c|c|c|c|c|c|c|c|}
\hline \multicolumn{5}{|c|}{ females (left) } & \multicolumn{5}{|c|}{ females (right) $^{\mathrm{a}}$} \\
\hline & $\mathbf{n}$ & $\mathbf{F}$ & $p$ & $\begin{array}{c}\text { Bonferroni } \\
\text { post hoc analysis }\end{array}$ & & $\mathbf{n}$ & $\mathbf{F}$ & $p$ & $\begin{array}{c}\text { LSD } \\
\text { post hoc analysis }\end{array}$ \\
\hline F35 & 19 & 1.914 & 0.171 & - & F35 & 14 & 4.270 & 0.042 & $\mathrm{~T}>\mathrm{M}$ \\
\hline $\mathrm{F} 50$ & 19 & 1.742 & 0.201 & - & F50 & 14 & 2.600 & 0.119 & - \\
\hline F65 & 19 & 0.093 & 0.963 & - & F65 & 14 & 1.201 & 0.338 & - \\
\hline H35 & 21 & 7.227 & 0.002 & $\mathrm{~K}>>\mathrm{T}$ & H35 & 12 & 6.134 & 0.021 & $\mathrm{~K} \gg \mathrm{T}$ \\
\hline $\mathrm{H} 50$ & 21 & 5.925 & 0.006 & $\mathrm{~T}>\mathrm{G}$ & $\mathrm{H} 50$ & 12 & 5.846 & 0.024 & $\mathrm{~T}>\mathrm{K}, \mathrm{M}$ \\
\hline $\mathrm{H} 65^{\mathrm{b}}$ & 21 & 4.120 & 0.023 & $\mathrm{~T}>\mathrm{G}$ & H65 & 12 & 4.462 & 0.045 & $\mathrm{~T}>\mathrm{M}$ \\
\hline \multicolumn{5}{|c|}{ males (left) } & \multicolumn{5}{|c|}{ males (right) $^{\mathrm{a}}$} \\
\hline F35 & 14 & 1.410 & 0.297 & - & F35 & 9 & 2.424 & 0.169 & - \\
\hline $\mathrm{F} 50$ & 14 & 1.216 & 0.354 & - & $\mathrm{F} 50^{\mathrm{b}}$ & 9 & 3.426 & 0.102 & - \\
\hline F65 & 14 & 0.089 & 0.964 & - & F65 & 9 & 0.517 & 0.621 & - \\
\hline $\mathrm{H} 35^{\mathrm{b}}$ & 14 & 3.304 & 0.066 & - & H35 & 9 & 3.231 & 0.112 & - \\
\hline H50 & 14 & 2.081 & 0.166 & - & H50 & 9 & 1.408 & 0.315 & - \\
\hline H65 & 14 & 0.621 & 0.617 & - & H65 & 9 & 2.080 & 0.206 & - \\
\hline
\end{tabular}

$\mathrm{G}=$ Gombe, $\mathrm{K}=$ Kibale, $\mathrm{M}=$ Mahale, $\mathrm{T}=$ Taï; $\mathrm{F}=$ femur, $\mathrm{H}=$ humerus; 35 = mid-distal diaphysis, 50 = midshaft, 65 = mid-proximal diaphysis. ${ }^{\mathrm{a}}$ Gombe individuals excluded from comparisons.

bFailed a Levene test of homogeneity of variances, thus when ANOVA was significant a Tamhane's T2 post hoc analysis was conducted. 
Table 7. Community sex-specific comparisons in percent cortical bone (\%CA)

\begin{tabular}{|c|c|c|c|c|c|c|c|c|c|}
\hline \multicolumn{5}{|c|}{ females (left) } & \multicolumn{5}{|c|}{ females (right) ${ }^{\mathrm{a}}$} \\
\hline & $\mathbf{n}$ & $\mathbf{F}$ & $p$ & $\begin{array}{c}\text { Bonferroni } \\
\text { post hoc analysis }\end{array}$ & & $\mathbf{n}$ & $\mathbf{F}$ & $p$ & $\begin{array}{c}\text { LSD } \\
\text { post hoc analysis }\end{array}$ \\
\hline $\mathrm{F} 35^{\mathrm{b}}$ & 19 & 4.576 & 0.018 & $\mathrm{~T}>\mathrm{G}$ & $\mathrm{F} 35^{\mathrm{b}}$ & 14 & 0.561 & 0.586 & - \\
\hline F50 & 19 & 4.858 & 0.015 & $\mathrm{M}, \mathrm{T}>\mathrm{G}$ & $\mathrm{F} 50^{\mathrm{b}}$ & 14 & 0.469 & 0.637 & - \\
\hline $\mathrm{F} 65^{\mathrm{b}}$ & 19 & 4.906 & 0.014 & $\mathrm{~T}>\mathrm{G}$ & $\mathrm{F} 65^{\mathrm{b}}$ & 14 & 0.443 & 0.653 & - \\
\hline H35 & 21 & 6.318 & 0.004 & $\mathrm{~T}>>\mathrm{G} ; \mathrm{K}, \mathrm{M}>\mathrm{G}$ & $\mathrm{H} 35^{\mathrm{b}}$ & 12 & 0.371 & 0.700 & - \\
\hline $\mathrm{H} 50$ & 21 & 8.137 & 0.001 & $\mathrm{M}, \mathrm{T} \gg \mathrm{G} ; \mathrm{K}>\mathrm{G}$ & $\mathrm{H} 50^{\mathrm{b}}$ & 12 & 0.017 & 0.983 & - \\
\hline $\mathrm{H} 65$ & 21 & 7.757 & 0.002 & $\mathrm{M}, \mathrm{T}>>\mathrm{G} ; \mathrm{K}>\mathrm{G}$ & $\mathrm{H} 65^{\mathrm{b}}$ & 12 & 0.078 & 0.926 & - \\
\hline \multicolumn{5}{|c|}{ males (left) } & \multicolumn{5}{|c|}{ males (right) $^{\mathrm{a}}$} \\
\hline F35 & 14 & 0.044 & 0.987 & - & F35 & 9 & 0.099 & 0.907 & - \\
\hline F50 & 14 & 0.370 & 0.777 & - & F50 & 9 & 0.657 & 0.552 & - \\
\hline F65 & 14 & 0.804 & 0.520 & - & F65 & 9 & 0.502 & 0.629 & - \\
\hline H35 & 14 & 0.871 & 0.488 & - & $\mathrm{H} 35^{\mathrm{b}}$ & 9 & 0.396 & 0.689 & - \\
\hline $\mathrm{H} 50$ & 14 & 1.690 & 0.232 & - & $\mathrm{H} 50$ & 9 & 0.662 & 0.550 & - \\
\hline H65 & 14 & 2.119 & 0.161 & - & H65 & 9 & 0.039 & 0.962 & - \\
\hline
\end{tabular}

$\mathrm{G}=$ Gombe, $\mathrm{K}$ = Kibale, $\mathrm{M}$ = Mahale, $\mathrm{T}$ = Taï; $\mathrm{F}$ = femur, $\mathrm{H}$ = humerus; 35 = mid-distal diaphysis, 50 = midshaft, 65 = mid-proximal diaphysis. ${ }^{\mathrm{a}} \mathrm{Gombe}$ individuals excluded from comparisons.

${ }^{b}$ Failed a Levene test of homogeneity of variances, thus when ANOVA was significant a Tamhane's T2 post hoc analysis was conducted. 
Table 8. Sex-specific community means (1 s.d.) for normalized $I_{\max }$.

\begin{tabular}{|c|c|c|c|c|c|c|}
\hline & \multicolumn{6}{|c|}{$\begin{array}{c}\text { Females } \\
\end{array}$} \\
\hline & $\begin{array}{c}\text { Kibale } \\
\text { (left) }\end{array}$ & $\begin{array}{l}\text { Kibale } \\
\text { (right) }\end{array}$ & $\begin{array}{c}\text { Mahale } \\
\text { (left) }\end{array}$ & $\begin{array}{c}\text { Mahale } \\
\text { (right) }\end{array}$ & $\begin{array}{c}\text { Taï } \\
\text { (left) }\end{array}$ & $\begin{array}{c}\text { Taï } \\
\text { (right) }\end{array}$ \\
\hline \multirow{3}{*}{ F35 $I_{\max }$} & 1.04 & 1.06 & 1.00 & 1.05 & 1.53 & 1.40 \\
\hline & $(0.25)$ & $(0.17)$ & $(0.09)$ & $(0.05)$ & $(0.28)$ & $(0.21)$ \\
\hline & 3 & 3 & 3 & 3 & 3 & 4 \\
\hline \multirow[t]{3}{*}{$\mathrm{F} 50 \mathrm{I}_{\max }$} & 1.08 & 1.10 & 1.03 & 1.11 & 1.57 & 1.48 \\
\hline & $(0.23)$ & $(0.20)$ & $(0.14)$ & $(0.14)$ & $(0.29)$ & $(0.20)$ \\
\hline & 3 & 3 & 3 & 3 & 3 & 4 \\
\hline \multirow{3}{*}{ F65 I $I_{\max }$} & 1.10 & 1.10 & 1.09 & 1.12 & 1.48 & 1.41 \\
\hline & $(0.30)$ & $(0.28)$ & $(0.14)$ & $(0.09)$ & $(0.23)$ & $(0.15)$ \\
\hline & 3 & 3 & 3 & 3 & 3 & 4 \\
\hline \multirow[t]{3}{*}{$\mathrm{H} 35 \mathrm{I}_{\max }$} & 0.70 & 0.66 & - & - & 0.80 & 0.82 \\
\hline & $(0.07)$ & $(0.07)$ & & & $(0.09)$ & $(0.07)$ \\
\hline & 4 & 2 & & & 5 & 4 \\
\hline \multirow[t]{3}{*}{$\mathrm{H} 50 \mathrm{I}_{\max }$} & 0.76 & 0.71 & - & - & 0.98 & 1.01 \\
\hline & $(0.10)$ & $(0.13)$ & & & $(0.19)$ & $(0.19)$ \\
\hline & 4 & 2 & & & 5 & 4 \\
\hline \multirow{5}{*}{$\mathrm{H} 65 \mathrm{I}_{\max }$} & 0.75 & 0.74 & - & - & 0.97 & 0.98 \\
\hline & $(0.04)$ & $(0.03)$ & & & $(0.20)$ & $(0.21)$ \\
\hline & 4 & 2 & & & 5 & 4 \\
\hline & & & & & & \\
\hline & $\begin{array}{c}\text { Kibale } \\
\text { (left) }\end{array}$ & $\begin{array}{l}\text { Kibale } \\
\text { (right) }\end{array}$ & $\begin{array}{c}\text { Mahale } \\
\text { (left) }\end{array}$ & $\begin{array}{c}\text { Mahale } \\
\text { (right) }\end{array}$ & $\begin{array}{c}\text { Taï } \\
\text { (left) }\end{array}$ & $\begin{array}{c}\text { Taï } \\
\text { (right) }\end{array}$ \\
\hline \multirow[t]{3}{*}{ F35 $I_{\max }$} & 1.28 & 1.29 & 1.19 & 1.22 & 1.28 & 1.29 \\
\hline & $(0.15)$ & $(0.14)$ & $(-)$ & $(-)$ & $(0.44)$ & $(0.01)$ \\
\hline & 6 & 5 & 1 & 1 & 2 & 2 \\
\hline \multirow[t]{3}{*}{$\mathrm{F} 50 \mathrm{I}_{\max }$} & 1.29 & 1.26 & 1.20 & 1.25 & 1.30 & 1.33 \\
\hline & $(0.13)$ & $(0.09)$ & $(-)$ & $(-)$ & $(0.46)$ & $(0.07)$ \\
\hline & 6 & 5 & 1 & 1 & 2 & 2 \\
\hline \multirow{3}{*}{ F65 I $I_{\max }$} & 1.30 & 1.29 & 1.22 & 1.21 & 1.24 & 1.36 \\
\hline & $(0.12)$ & $(0.06)$ & $(-)$ & $(-)$ & $(0.25)$ & $(0.05)$ \\
\hline & 6 & 5 & 1 & 1 & 2 & 2 \\
\hline \multirow[t]{3}{*}{$\mathrm{H} 35 \mathrm{I}_{\max }$} & 0.84 & 0.86 & - & - & 0.78 & - \\
\hline & $(0.17)$ & $(0.17)$ & & & $(-)$ & \\
\hline & 6 & 6 & & & 1 & \\
\hline \multirow[t]{3}{*}{$\mathrm{H} 50 \mathrm{I}_{\max }$} & 0.87 & 0.85 & - & - & 0.97 & - \\
\hline & $(0.12)$ & $(0.11)$ & & & $(-)$ & \\
\hline & 6 & 6 & & & 1 & \\
\hline \multirow{3}{*}{$\mathrm{H} 65 \mathrm{I}_{\max }$} & 0.93 & 0.90 & - & - & 1.01 & - \\
\hline & $(0.12)$ & $(0.11)$ & & & $(-)$ & \\
\hline & 6 & 6 & & & 1 & \\
\hline
\end{tabular}


Table 9. Kruskal-Wallis tests for community sex-specific comparisons ${ }^{\mathrm{a}}$ in normalized $\mathrm{I}_{\max }$.

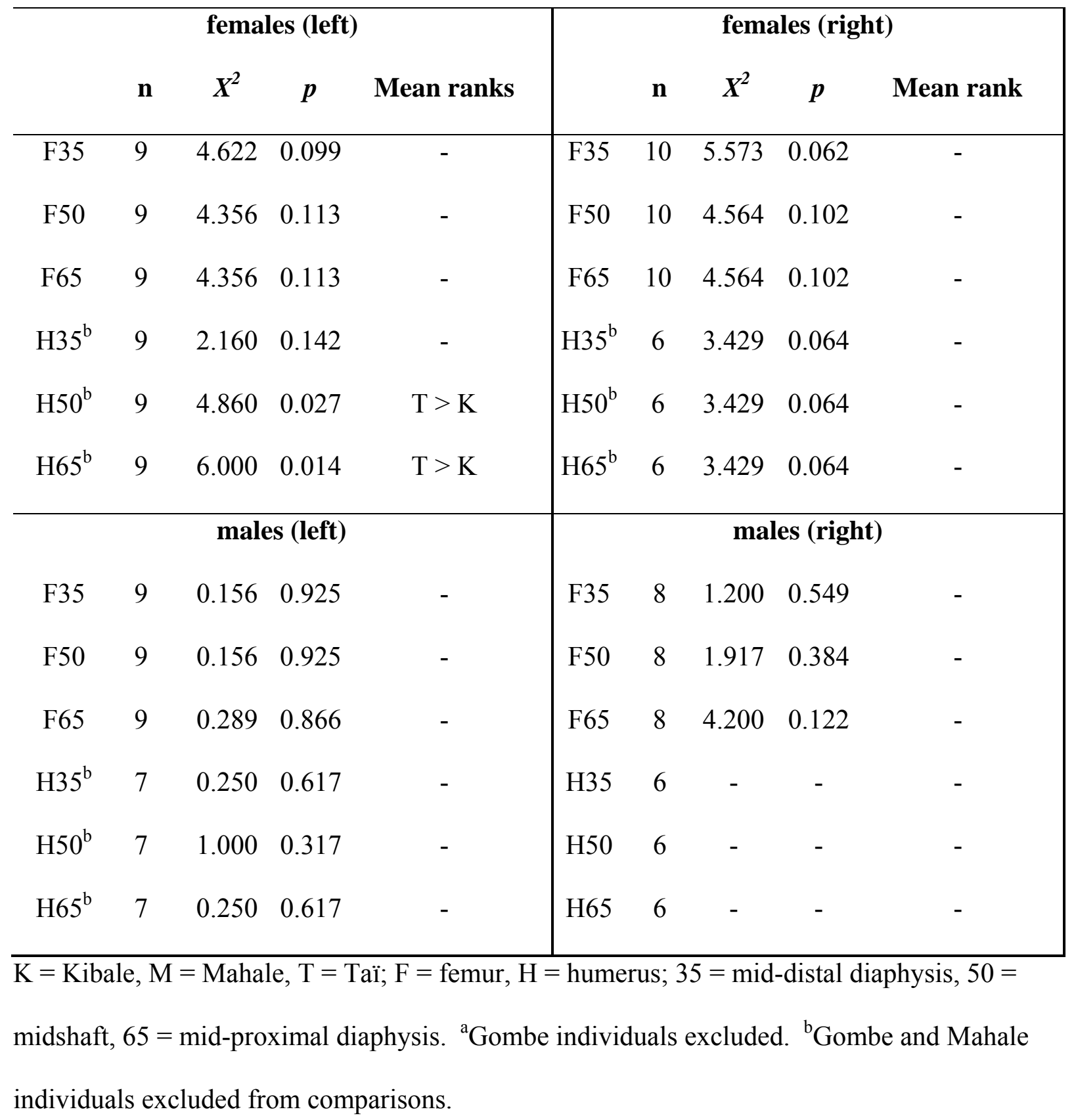


Table 10. Ranked shape ratios $\left(\mathrm{I}_{\max } / \mathrm{I}_{\min }\right)$ vs. ranked habitat characteristics.

\begin{tabular}{|c|c|c|c|c|}
\hline & Annual rainfall & Ground cover & Elevation range & Slope of terrain ${ }^{1}$ \\
\hline Community ranking & $\mathrm{M}>\mathrm{T}>\mathrm{G}>\mathrm{K}$ & $\mathrm{T}>\mathrm{M} \approx \mathrm{K}>\mathrm{G}$ & $\mathrm{M}>\mathrm{G}>\mathrm{K}>\mathrm{T}$ & $\mathrm{G}>\mathrm{M}>\mathrm{K}>\mathrm{T}$ \\
\hline \multirow[t]{2}{*}{ Left femur shape } & Female & $35 \%: \mathrm{T}=\mathrm{K}>\mathrm{G}>\mathrm{M}$ & $50 \%: \mathrm{T}>\mathrm{K}=\mathrm{G}>\mathrm{M}$ & $65 \%: \mathrm{K}>\mathrm{T}>\mathrm{G}>\mathrm{M}$ \\
\hline & Male & $35 \%: \mathrm{T}>\mathrm{K}>\mathrm{G}>\mathrm{M}$ & $50 \%: \mathrm{T}>\mathrm{G}>\mathrm{K}=\mathrm{M}$ & $65 \%: \mathrm{K}>\mathrm{G}>\mathrm{T}=\mathrm{M}$ \\
\hline \multirow[t]{2}{*}{ Right femur shape } & Female & $35 \%: \mathrm{T}>\mathrm{K}>\mathrm{M}$ & $50 \%: \mathrm{T}>\mathrm{K}>\mathrm{M}$ & $65 \%: \mathrm{T}>\mathrm{K}>\mathrm{M}$ \\
\hline & Male & $35 \%: \mathrm{T}>\mathrm{K}>\mathrm{M}$ & $50 \%: \mathrm{T}>\mathrm{M}>\mathrm{K}$ & $65 \%: \mathrm{T}>\mathrm{K}>\mathrm{M}$ \\
\hline \multirow[t]{2}{*}{ Left humerus shape } & Female & $35 \%: \mathrm{K}>\mathrm{M}>\mathrm{G}>\mathrm{T}$ & $50 \%: \mathrm{T}>\mathrm{K}>\mathrm{M}>\mathrm{G}$ & $65 \%: \mathrm{T}>\mathrm{K}>\mathrm{M}>\mathrm{G}$ \\
\hline & Male & $35 \%: \mathrm{K}>\mathrm{G}>\mathrm{M}>\mathrm{T}$ & $50 \%: \mathrm{T}>\mathrm{K}>\mathrm{M}>\mathrm{G}$ & $65 \%: \mathrm{K}>\mathrm{T}>\mathrm{M}>\mathrm{G}$ \\
\hline \multirow[t]{2}{*}{ Right humerus shape } & Female & $35 \%: \mathrm{K}>\mathrm{M}>\mathrm{T}$ & $50 \%: \mathrm{T}>\mathrm{K}>\mathrm{M}$ & $65 \%: \mathrm{T}>\mathrm{K}>\mathrm{M}$ \\
\hline & Male & $35 \%: K>T>M$ & $50 \%: \mathrm{T}>\mathrm{K}>\mathrm{M}$ & $65 \%: \mathrm{K}>\mathrm{M}>\mathrm{T}$ \\
\hline
\end{tabular}

$\overline{\mathrm{G}}=$ Gombe, $\mathrm{K}=$ Kibale, $\mathrm{M}=$ Mahale, $\mathrm{T}=$ Taï. ${ }^{1}$ Quantitative data on slope of terrain from Taï Forest National Park were unavailable, but based on elevation ranges, it seems reasonable to characterize terrain at Taï as flattest among the sites. 

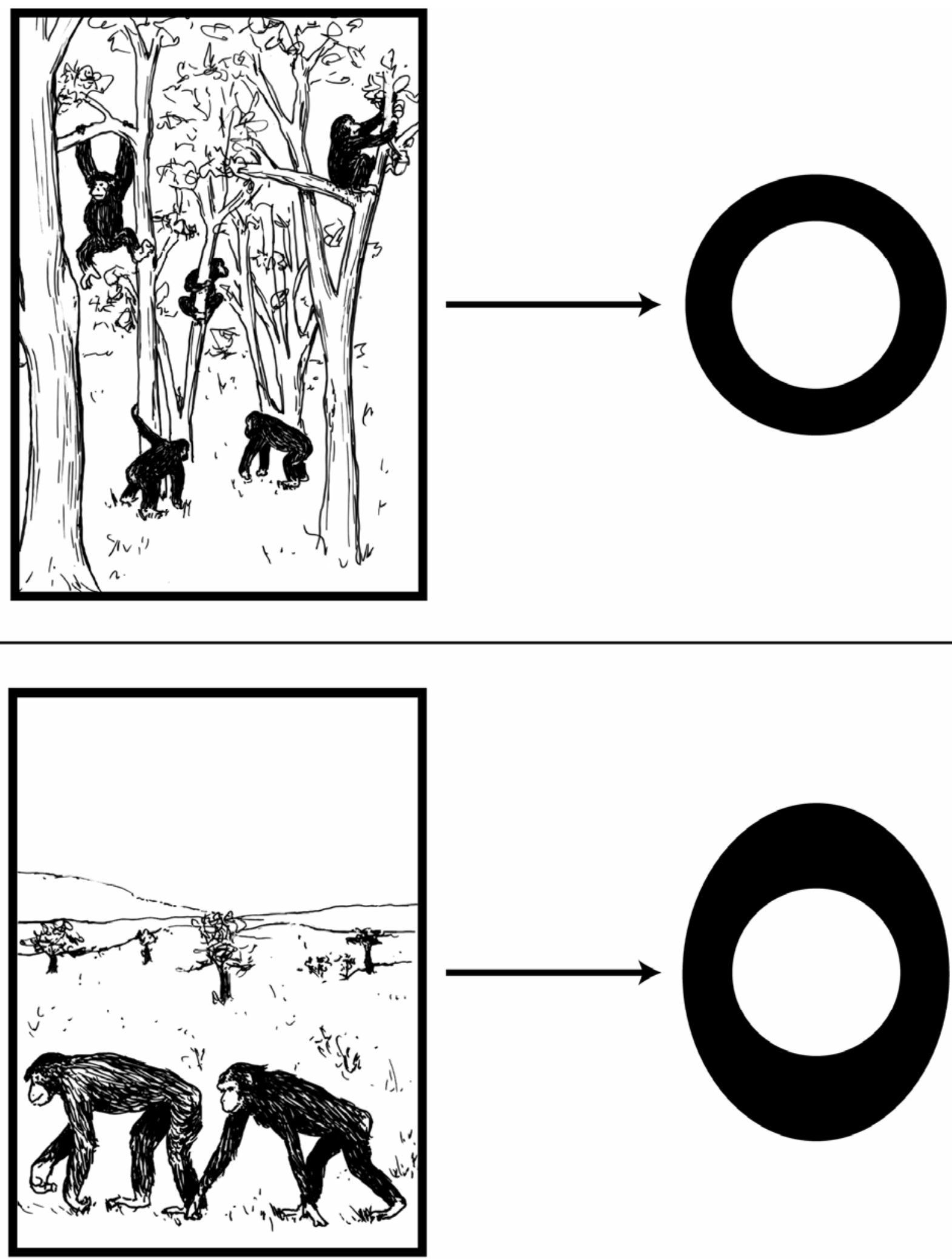

Figure 1. 